\title{
$\begin{array}{r}\text { WAGENINGEN } \\ \hline\end{array}$
}

\section{Moving beyond the shrimp farm: Spaces of shared environmental risk?}

Bottema, M. J. M., Bush, S. R., \& Oosterveer, P.

This article is made publically available in the institutional repository of Wageningen University and Research, under article $25 \mathrm{fa}$ of the Dutch Copyright Act, also known as the Amendment Taverne.

Article $25 \mathrm{fa}$ states that the author of a short scientific work funded either wholly or partially by Dutch public funds is entitled to make that work publicly available for no consideration following a reasonable period of time after the work was first published, provided that clear reference is made to the source of the first publication of the work.

For questions regarding the public availability of this article, please contact openscience.library@wur.nl.

Please cite this publication as follows:

Bottema, M. J. M., Bush, S. R., \& Oosterveer, P. (2018). Moving beyond the shrimp farm: Spaces of shared environmental risk? Geographical Journal. https://doi.org/10.1111/geoj.12280 


\title{
Moving beyond the shrimp farm: Spaces of shared environmental risk?
}

\author{
Mariska J. M. Bottema (iD | Simon R. Bush | Peter Oosterveer
}

Environmental Policy Group, Wageningen University and Research, Wageningen, The Netherlands

\section{Correspondence}

Mariska J. M. Bottema

Email: mariska.bottema@wur.nl

\section{Funding information}

The Netherlands Organisation for Scientific Research (NWO); New Directions in Environmental Governance (NDEG) at the York Centre for Asian Research; CGIAR Research Program on Fish Agrifood Systems (FISH)
Key environmental challenges faced by the aquaculture sector demonstrate that aquaculture production is not isolated from the surrounding environment, and we see a policy shift towards area-based approaches. However, without an understanding of the farmer's perspective, there is a danger of misrepresenting how farm-level practices relate to area-based approaches and to environmental risk management. This paper empirically examines how individual aquaculture farmers interpret and manage environmental risks and the extent to which they operate beyond the boundaries of their farms. The analysis is based on a comparison between intensive aquaculture farmers in Kung Krabaen Bay, Thailand, representing an area of closed production systems; and a mixture of integrated mangrove shrimp and extensive shrimp farmers in Kien Vang Forest, Vietnam, representing an area of open production systems. Data were collected through semi-structured interviews and participatory mapping. The spatial configuration of environmental risk management in both areas demonstrated a focus on the farm. Though farmers did recognise off-farm risks, this did not result in collectively practised risk management strategies at a broad landscape scale. These observations demonstrate the need to rethink the development of area-based approaches for both closed and open systems. Instead of the designation of aquaculture zones or all-encompassing integrated landscape models of area-based management, the findings suggest an alternative model. This third way of conceptualising spatial models of area-based aquaculture management is based on a nested set of areas within a landscape defined by the socio-spatial extent of farmer networks within which the interpretation of risk is homogeneous.

\section{K E Y W O R D S}

area management, environmental risk management, shrimp aquaculture, space, Thailand, Vietnam

\section{1 | INTRODUCTION}

The primary unit of aquaculture production has traditionally been understood as the territory of the farm. Consequently, environmental problems have also been largely dealt with by interventions targeting farm-scale production practices (Anh et al., 2011; Soto et al., 2008). However, the key challenges faced by the sector, including disease and water quality, demonstrate that aquaculture production is not isolated from the surrounding environment (Subasinghe et al., 2009). Building on concepts such as agro-ecology (Tomich et al., 2011), landscape management (Freeman et al., 2015) and traditional spatial 
planning, NGOs and governments alike have shifted their attention to area-based forms of management to overcome a range of these risks (Aguilar-Manjarrez et al., 2017; Sustainable Fisheries Partnership, 2018; The Nature Conservancy, 2017).

The degree to which a farm is integrated into a larger area depends on physical and social factors. First, the embeddedness of a farm within a landscape depends on the degree to which a farm is physically "open" or "closed" to the surrounding environment (Bush et al., 2010; Vandergeest et al., 2015). Intensive closed systems are characterised by high stocking densities and limited physical interactions between farms and surroundings. Extensive open systems are characterised by minimal inputs and frequent physical interactions between farms and surroundings (Joffre et al., 2015). All systems along this open-closed spectrum are, however, embedded in a set of environmental risks that force farmers to adopt both on- and off-farm management practices (Soto et al., 2008; Waite et al., 2014). Aquaculture farms can therefore be understood (to varying degrees) as environmentally permeable units. As such, boundaries delineating the farm as the unit of production and management become less clearly defined.

Second, a farm's embeddedness is also dependent on the degree to which social relations between farmers influence both on- and off-farm risk management decisions (Adger, 2003). It is assumed that the degree of collaboration to mitigate risks corresponds to how open or closed a system is. The more open a system, the more intense collaboration should be to reduce mutual impact (Bush et al., 2010). While the importance of collaboration has been observed, much of the existing literature explores risk in aquaculture production in quantified, farm-level measures of risk perception, attitude and management (Ahsan, 2011; Joffre et al., 2018; Le Bihan et al., 2013). However, these studies do not explore all the environmental risks that farmers encounter, nor do they make their spatiality explicit. Furthermore, these studies do not focus on whether farmers manage environmental risks individually, collectively or otherwise.

By ignoring the farmer's perspective, we argue there is a danger of misrepresenting how farm-level practices relate to area-based approaches to environmental risk management. This paper addresses this gap by empirically examining how individual aquaculture farmers interpret and manage environmental risks, and the extent to which they operate beyond the boundaries of their farms, using an interpretative and relational approach. In taking this approach, we critically examine preconceived ideas about "farm-level" production space. We do this by determining how production spaces are defined by farmers themselves and the extent to which social relations enable or constrain farmers to deal with environmental risks.

Our analysis is based on a comparison between intensive shrimp and grouper farmers in Kung Krabaen Bay, Thailand, and integrated mangrove shrimp (IMS) and extensive shrimp farmers in Kien Vang Forest, Vietnam. Kung Krabaen Bay represents an area with closed production systems, with clear delineation of farm boundaries and highly regulated water management. In contrast, Kien Vang Forest represents an area with open production systems, less clearly defined farm boundaries and less regulated water management. These differences are expected to result in two dissimilar situations in terms of the location of environmental risks in the landscape, the consequent activities farmers practise to manage these risks, and the social relations farmers pursue to deal with them.

The following section presents the analytical framework for understanding aquaculture production space. In the third section we describe methods of data collection and analysis. We then elaborate on the spatial distribution of production systems and institutional setting in the two cases before presenting our findings on the spatial and relational configuration of environmental risk management in the fifth section. The sixth section discusses how farmers set boundaries through risk management in open and closed systems, and we reflect on how this matches with what we expect to find in area-based approaches. The final section reflects on the contribution of our findings to contemporary debates around area-based approaches in aquaculture.

\section{2 | AQUACULTURE SPACE, ENVIRONMENTAL RISKS AND SOCIAL RELATIONS}

The dichotomy of open and closed farms implies two forms of area-based management. In its ideal state, integrated landscape management (which we take to include landscape and agro-ecological approaches), corresponding to open systems, engages all stakeholders and reconciles trade-offs between different land uses, thereby integrating agricultural and environmental priorities (Sayer et al., 2013). Actors organise themselves around consensual boundaries and risks are addressed through collaborative relations. Alternatively, conventional spatial planning, corresponding to closed systems, relies on models developed by experts to deliver optimal solutions and often segregates protected and productive areas, isolating production from vulnerable ecosystems (Sayer et al., 2013). The closed nature of systems thus arguably diminishes the need for collaboration between farmers. 
We use this dichotomy to examine whether assumptions about environmental risk management in closed and open systems hold. In doing so, we assume space and risk to be interpretative and relational. First, risks are concurrently material and social. Risk interpretation is how farmers anticipate the outcomes of choices made, by themselves or by other decisionmakers, in the face of uncertain events (Elliott \& Pais, 2006; Kjærnes, 2006; Richard Eiser et al., 2012). Second, there is no one space; there are multiple co-existing spaces that change over time (Massey, 2005; Murdoch, 1998). Each farmer has his or her own interpretation of space, which is dynamic and shaped by the material and social context. Third, this view of space presents alternative territorial units which go beyond rigid farm boundaries and lead to constantly shifting concerns (Bear, 2013; Kidd \& Shaw, 2013; Vandergeest et al., 2015). Risks in aquaculture production are therefore no longer limited to individual on-farm issues. They include risks outside the farm which can involve multiple actors. Thus, changes in the understanding of aquaculture production space influences which risks are recognised, as well as the strategies applied and relations sought to address them.

To understand how environmental risk management is spatially organised in closed and open systems, we first group environmental risks into three spatial categories. We classify environmental risks as production risks, which affect the volume or quality of production (Hardaker et al., 1997; World Bank Group, 2016). Based on a review of literature and certification schemes we distinguish between three, sometimes overlapping, categories (Aquaculture Stewardship Council, 2014; Arthur et al., 2009; Best Aquaculture Practices, 2014; Bostock et al., 2010; GLOBAL G.A.P., 2012; Naturland, 2016). The first are environmental risks flowing into the farm from the surroundings and manifested on-farm; for example, poor quality or disease-carrying inputs and climate-related risks. The second are environmental risks caused by the farm, manifested as impacts outside the farm, such as waste and water disposal. Third, there are environmental risks transferred between farms, such as disease.

The second step in understanding the spatial configuration of environmental risk management is determining where farmers intervene to address these three flows of risk: on-farm or off-farm. Lebel et al. (2016) distinguish between strategies applied at farm-scale and those applied at watershed-scale. However, risk management practices (RMPs) may also be carried out further away. In this investigation we distinguish between RMPs practised on-farm and those practised off-farm. We hypothesise that farms with open systems apply more RMPs outside the farm than farms with closed systems, since the effectiveness of their on-farm RMPs is inherently limited.

Third, we distinguish between three risk management strategies: individually practised, externally practised and collectively practised RMPs. Individually practised RMPs, frequently applied in aquaculture management (Bergfjord, 2009), present the farm as the only unit of decision-making in mitigating risk. External RMPs are those practised or facilitated by external actors. Norms and sanctions set by external actors can act as institutions which shape farmers' responses to risk (Lo \& Chan, 2017). Relations of reciprocity between a farmer and another actor may also result in RMPs carried out by this external actor. Collective RMPs are carried out collaboratively by multiple farmers. Networked relations, as exhibited by farmer groups or collectives, may facilitate the formulation of shared norms, information sharing and collective management (Lo \& Chan, 2017). Based on research by Bush et al. (2010), we hypothesise that farmers in open systems apply more collective strategies to mitigate environmental risks than farmers in closed systems, and we predict that the diversity of the landscape contributes to advancing their capacity for self-organisation.

\section{3 | METHODOLOGY}

Following a scoping study in search of illustrative examples of aquaculture area management in Vietnam, Thailand and Bangladesh carried out in June 2016, Kung Krabaen Bay and Kien Vang Forest were selected as two exceptional cases in which there were efforts to solve environmental problems at a spatial level beyond the farm. Kung Krabaen Bay represented an area dominated by closed production systems and Kien Vang Forest an area of open production systems.

Farmers were sampled and interviewed in two steps. First, government agencies responsible for area management, the Department of Fisheries (DoF) in Kung Krabaen Bay and the Forest Management Board (FMB) in Kien Vang Forest, were interviewed to understand the spatial distribution of farmers and environmental risks and to select farmer respondents. Government representatives in both areas claimed that there was no significant variation in terms of environmental risks throughout the areas. At the time of the research many of the farms in Kung Krabaen Bay were empty due to seasonality, so farmers were sampled from three of the eight user groups of the local irrigation system because there was a relatively large number of members present. Farmers in Kien Vang Forest were randomly sampled from three sub-areas of Kien Vang Forest. These sub-areas were selected because they contained both farmers who had Selva Shrimp certification, a form of organic group certification, and those who did not. 
Second, 20 aquaculture farmers were interviewed at each study site between January and May 2017. In Kung Krabaen Bay, 18 shrimp farmers and two grouper farmers were interviewed. In Kien Vang Forest, 18 IMS farmers and two extensive shrimp farmers were interviewed. Semi-structured interviews with individual farmers based on prompting lists of environmental risks were used to understand the risks they experienced and the management practices they applied to mitigate them. Interviews included a participatory mapping exercise using cadastral, bay and commune level maps to clarify the location of RMPs, actors in the landscape, and with whom farmers communicated about environmental risks. On the basis of these maps, a walk in or around the farm was made with farmers where information from the interviews was verified. It was concluded after the 20 interviews that the variation in responses was no longer high enough to warrant additional interviews.

All interviews and digitised participatory maps were coded and analysed using ATLAS.ti software. The codes used correspond directly to the themes within the three parts of the analytical framework. Environmental risks were weighted and ranked according to the risk magnitudes assessed by the respondents, ranging from zero risk to very high risk, and to the number of respondents experiencing them. RMPs described in interviews were ranked according to the number of respondents applying them.

\section{4 | CONTEXTUALISING ENVIRONMENTAL RISKS IN KUNG KRABAEN BAY AND KIEN VANG FOREST}

\section{1 | Kung Krabaen Bay: An area of closed systems}

Kung Krabaen Bay represents an area of highly institutionalised, spatially bounded aquaculture production (Figure 1). In response to mangrove clearance and unplanned shrimp farming, the Kung Krabaen Bay Royal Development Study Centre was founded in 1981 to serve as a shrimp culture demonstration area. According to Boonsong (1997), in 1987, about 166 hectares
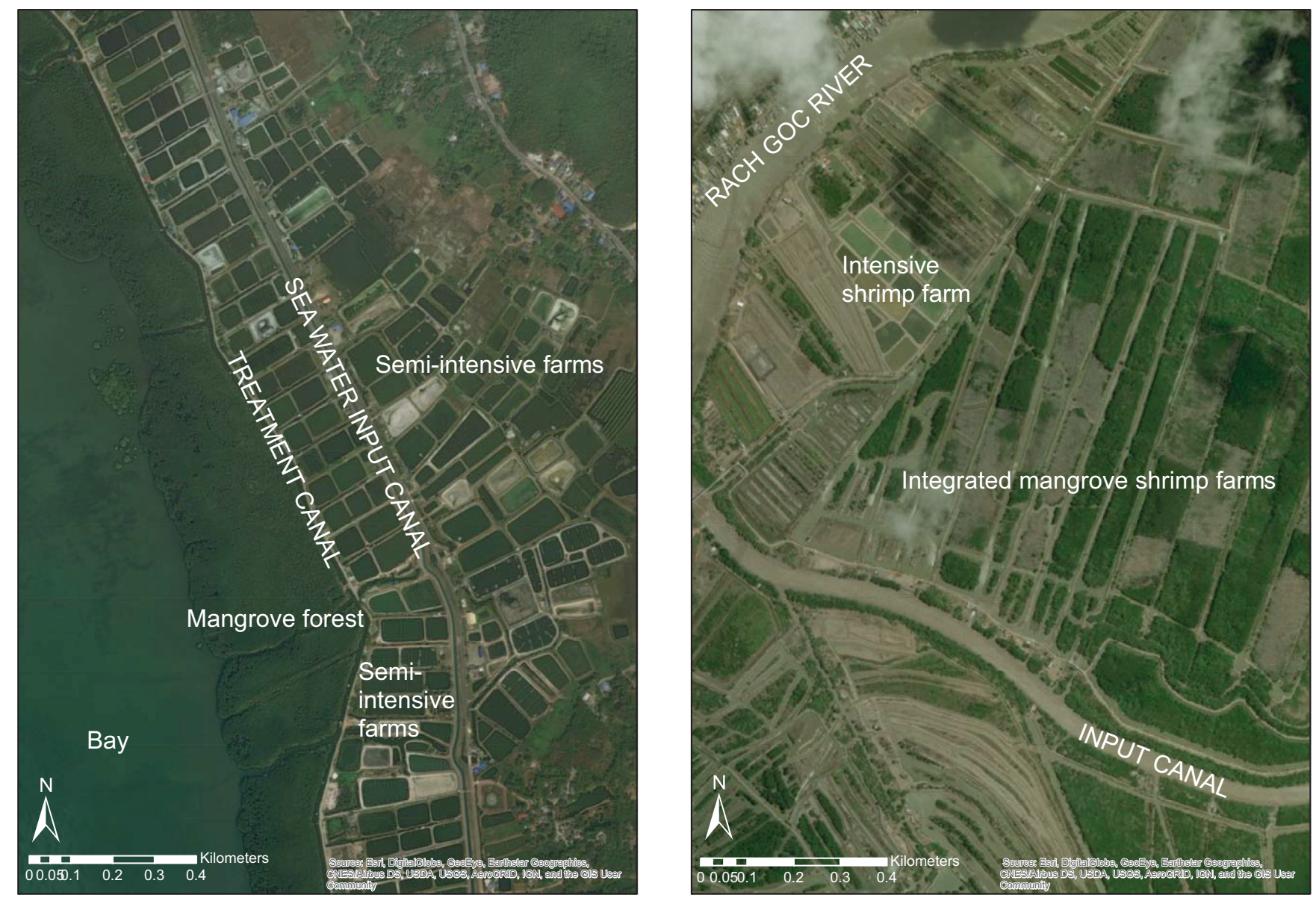

F I G URE 1 Image of characteristic aquaculture landscape in Kung Krabaen Bay, Chantaburi (left) and Kien Vang Forest, Ca Mau (right). Source: Esri, DigitalGlobe, GeoEye, Earthstar Geographics, CNES/Airbus DS, USDA, USGS, AeroGRID, IGN and the GIS User Community. 
of the bay's inland portion of deteriorated mangrove forest was allocated for a shrimp culture project managed by the DoF, while a fringe of bay-side forest was maintained for conservation and restoration.

Despite a high level of oversight provided by the Centre and DoF, the lack of sound wastewater management led to deterioration of water quality, self-contamination and high disease incidence (Boonsong, 1997; Satumanatpan et al., 2011). In 2001, the Royal Thai Government built a seawater irrigation system. Offshore seawater is pumped to shore, tested by the DoF and distributed through an input canal. Effluent from farms is treated in a separate treatment canal (Satumanatpan et al., 2011). Farmers are grouped into eight user groups, pay a fee and follow waste management regulations, such as building sedimentation areas for sludge.

Kung Krabaen Bay is spatially bounded at two levels: bay and farm level. The 15 square kilometres of the bay, fringed with a mangrove forest, is entirely dedicated to fisheries and aquaculture (Tookwinas \& Songsangjinda, 1999). There are 210 intensive shrimp and fish farms. Farm sizes among the respondents ranged from 0.4 to 3.2 hectares. Each farmer must use water from the irrigation system, which eliminates water transfer between farms, thereby closing off farms.

\subsection{Kien Vang Forest: An area of open systems}

Kien Vang Forest is dominated by open, integrated production systems (Figure 1). The forest lies in a coastal zone dedicated mainly to IMS farming. The Vietnamese government assigned these areas to create livelihood opportunities through shrimp farming, while conserving mangrove forest (Tran Thi Thu Ha et al., 2012). In the study area, IMS farmers were required to protect mangroves on at least $60 \%$ of their land (Quoc Vo et al., 2015). Shrimp production on the remaining $40 \%$ was their primary income source.

The FMB manages forest in Tan An commune, Tam Giang Tay commune and Rach Goc town. IMS farmers are contracted by the FMB under "Green Book" tenure, which stipulates the forest-to-pond area ratio, tree density and timber-marketing conditions (Joffre et al., 2015). Extensive farmers produce on land owned by the People's Committee under "Red Book" tenure, which stipulates less stringent regulations. All farming activities must also adhere to provincial regulations that seek to minimise production risk (Ha et al., 2014). For instance, the Ca Mau People's Committee stipulates that farmers must follow a seasonal calendar for dredging, and instructs farmers to arrange storage areas for sludge.

Kien Vang Forest features IMS farms and extensive shrimp farms, with a small number of intensive farmers, hatcheries and factories in designated zones. Like extensive shrimp farmers, the 866 IMS farms in Kien Vang Forest often combine shrimp culture with other aquatic species. Farms are established along brackish water estuaries. Farm sizes among respondents ranged from 2.5 to 13 hectares. These ponds connect to estuaries by gates which control water inflow and outflow according to tides (Blueyou Consulting Ltd., 2016). Primary water sources for aquaculture farmers in the study area are several sea gates and Rach Goc river.

\section{5 | THE SPACES OF ENVIRONMENTAL RISK MANAGEMENT}

\section{1 | On-farm risk management practices}

The location of environmental risks and RMPs described by farmers demonstrates that farmers are primarily focused on the space inside their farm. In both areas, over $70 \%$ of environmental risks described flow from the surroundings to the farm. In Kung Krabaen Bay 12\% and in Kien Vang Forest only 3\% of risks described flow from farm to environment. In terms of risk management, in Kung Krabaen Bay 88\% and in Kien Vang Forest 74\% of RMPs described were carried out on the farm.

In both cases, the majority of on-farm RMPs were carried out individually (Figure 2). These individually practised onfarm RMPs varied between the two areas due to the nature of production systems and risks experienced. This can be illustrated though a comparison of biosecurity and water management. Biosecurity RMPs were central in both cases, but were applied more frequently in Kung Krabaen Bay, since those farms had many options for preventing disease, such as nets and plastic linings (see Piamsomboon et al. (2015) for further detail). In contrast, RMPs to prevent disease in Kien Vang Forest mainly involved minimising water exchange.

Farmers in Kien Vang Forest experienced higher risks from poor quality of input water than farmers in Kung Krabaen Bay, but due to the open nature of production systems, controlling water quality was difficult. In Kung Krabaen Bay, 80\% of respondents did not see poor quality of input water as a risk, and if they did, farmers filtered or treated input water. In contrast, farmers in Kien Vang Forest ranked poor water quality stemming from water disposal by intensive shrimp farms, 


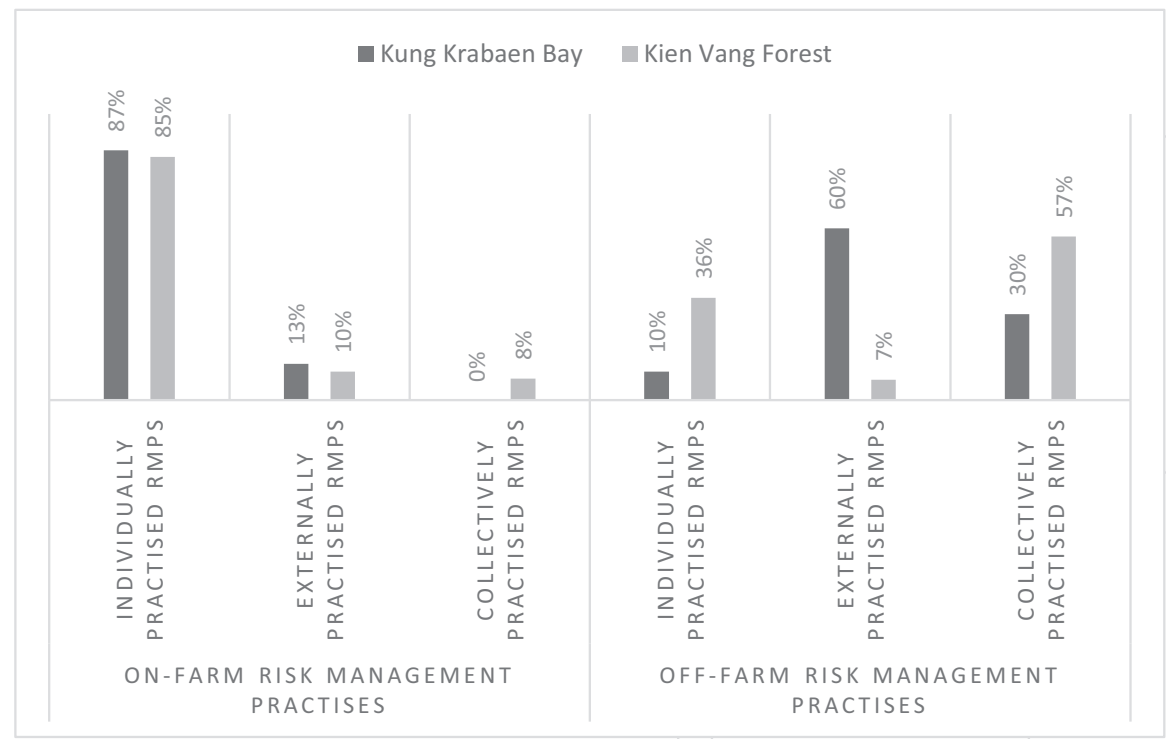

F IGURE 2 Distribution of on-farm and off-farm risk management practices in Kung Krabaen Bay and Kien Vang Forest.

hatcheries and factories as a high risk. However, due to the size and open nature of ponds, practices to improve water quality like those applied in Kung Krabaen Bay were inapplicable for respondents in Kien Vang Forest.

Farmers in both areas believed that physical location influenced their vulnerability to certain environmental risks. However, challenges related to physical location (for example, proximity to pollution sources such as sea gates) were more prominent and played a bigger role in determining RMPs in Kien Vang Forest than they did in Kung Krabaen Bay. This can be explained by the openness of production systems and dependency on the nature of the hydrological system in Kien Vang Forest, which led to more environmental interactions and consequentially greater vulnerability to off-farm risks.

External actors, particularly the government, also played a role in on-farm RMPs in both areas. In both cases the government formulated and enforced regulations for wastewater management, mangrove conservation and pond management. As such, formalised norms prescribed the way farmers should manage on-farm risks. However, in Kung Krabaen Bay, the role of government actors extended beyond these formalised norms. The DoF helped farmers manage the risk of poor quality post-larvae, which was the highest ranked risk. Farmers trusted the DoF, who played an active role in advising farms. In Kien Vang Forest, the FMB and the district level Department of Agriculture and Rural Development did not support farmers in this way.

Processing companies also played a notable role in on-farm risk management in both cases. Though not described specifically as RMPs by farmers, processing companies stipulated rules for on-farm risk management. In Kung Krabaen Bay, farmers who were members of Pracharat (a public-private partnership among the DoF, the Centre, the Kung Krabaen Fisheries Cooperative and Charoen Pokphand Group [CP]) applied biosecurity RMPs stipulated by CP. The Cooperative also set on-farm biosecurity RMPs as conditions for loans. Similarly, in Kien Vang Forest, Minh Phu Seafood Corporation collaborated with Blueyou Consulting and the FMB to certify 387 farms to produce Selva Shrimp. Certified farms were grouped and applied on-farm RMPs, for example prohibiting chemical use, stipulated in the Selva Shrimp standard.

Feed suppliers played a role in on-farm risk management in Kung Krabaen Bay, but not in Kien Vang Forest, since IMS and extensive farms in this area depend on natural feed. In Kung Krabaen Bay, feed suppliers tested water quality and shrimp health for free, as part of the service provided to farmers in exchange for buying feed, a role common to feed suppliers in the shrimp industry.

In Kung Krabaen Bay none of the on-farm RMPs were practised collectively, while in Kien Vang Forest $8 \%$ of on-farm RMPs were carried out collectively. Farmers in Kien Vang Forest coordinated dredging and water discharge. More than half of respondents in Kien Vang Forest who dredged claimed they coordinated the rental of dredging machines with others, to minimise costs and to deal with challenges related to spatial distribution of farms. Dredging machine transportation often required travelling through other farms, requiring coordination. About $60 \%$ of respondents claimed they coordinated water discharge with neighbours to address the risk of dykes breaking from water pressure differences caused by uncoordinated discharge. Half of these farmers stated this coordination took place through informal agreements between neighbours, while 50\% stated coordination emerged naturally, since the tide prescribed discharge timing. 
In Kien Vang Forest a number of informal and formal groups also set norms for collective or coordinated on-farm risk management, due to shared disease risks. For example, Dai Hiep Cooperative set rules for common water management to reduce disease transfer between farms, and members were encouraged to coordinate stocking post-larvae. Similarly, some Selva Shrimp certified farmers stocked simultaneously with other farmers in their group, due to coordinated delivery of post-larvae from Minh Phu.

\section{2 | Off-farm risk management practices}

Off-farm RMPs were more frequently applied in Kien Vang Forest than in Kung Krabaen Bay. In Kien Vang Forest 26\% and in Kung Krabaen Bay 12\% of RMPs were practised outside the farm. This difference can be explained by material characteristics of the production systems and the local contexts. Due to the open nature of farms, farmers in Kien Vang Forest could not apply some on-farm RMPs that intensive farms commonly apply to keep out environmental risks. Furthermore, farmers in Kien Vang Forest were faced with specific risks like produce theft and illegal wastewater disposal, which demanded action outside farm boundaries.

The social configuration of off-farm RMPs differed considerably from that of on-farm RMPs; the majority were practised collectively or by external actors (Figure 2). There was a notable difference between the two cases. In Kung Krabaen Bay, off-farm RMPs were mostly practised by external actors, followed by those practised collectively and individually. In Kien Vang Forest most off-farm RMPs were practised collectively, followed by those practised individually and externally.

There were more off-farm RMPs practised individually in Kien Vang Forest than in Kung Krabaen Bay. In Kien Vang Forest these were individual strategies for selecting post-larvae and individual reporting of problems regarding water pollution to the local government. These were not mentioned among respondents in Kung Krabaen Bay, where farmers talked more about the role post-larvae suppliers played in managing post-larvae quality outside the farm, and where farmers did not experience risks associated with water pollution in the same way as farmers in Kien Vang Forest.

External actors played a major role in off-farm RMPs in Kung Krabaen Bay, while they played a smaller role in Kien Vang Forest. In Kung Krabaen Bay, the government managed the irrigation system which arguably mitigated key risks. Farmers stated that the system supplies clean water, irrigation canals perform water catchment services and the treatment canal performs waste management services. Three of the four respondents who cultured shrimp before the irrigation system was built stated that disease transfer decreased after the irrigation system was constructed. Farmers in Kien Vang Forest, by contrast, expressed their lack of faith in the local government's capacity to address the poor quality of input water. Despite formal regulations for waste management and an Environmental Monitoring Group, assigned by the commune government to monitor wastewater management, farmers claimed that it was very difficult to enforce regulations. Consequentially, farmers searched for other ways to address this problem.

In both cases farmers described the role suppliers played in managing post-larvae quality. Trust in post-larvae suppliers was constant throughout respondents in Kung Krabaen Bay, but varied in Kien Vang Forest. Despite poor quality of postlarvae ranking as the highest risk in Kung Krabaen Bay, farmers had confidence that suppliers tested their product. Post-larvae suppliers were required to show farmers test results from the DoF. RMPs carried out by suppliers in Kien Vang Forest naturally differed due to the dissimilar nature of their production systems, and involved matching conditions of their nursery ponds to water conditions in the area. Trust in post-larvae suppliers varied among respondents; some farmers suspected suppliers of misleading them, while others trusted suppliers based on longstanding working relations, brand or relations of kinship.

Farmers in neither area reported the stipulation of rules for off-farm risk management or risk sharing by processing companies. Though $\mathrm{CP}$ and Minh Phu provided training to teach farmers dredging techniques, hygienic farm management and appropriate stocking and harvesting schedules, they did not set conditions for off-farm risk management.

Instead of depending on external actors to manage risks outside the farm, farmers in Kien Vang Forest placed emphasis on the application of collective risk management. This can in part be explained by the perceived lack of capacity of the local government to address certain risks in Kien Vang Forest, but can also be attributed to the nature of the environmental risks experienced. The most important risk farmers in Kien Vang Forest addressed collectively is the poor quality of input water caused by discharging of wastewater by intensive shrimp farms, factories and hatcheries. Respondents described informal local systems of surveillance whereby IMS and extensive farmers warned each other when intensive shrimp farms were suspected of releasing water illegally. Farmers stated that they collectively approached local government when problems occurred by raising them at Farmer Association or village meetings. However, farmers reported the local government did not have the authority to take the necessary action and described how sometimes farmers took matters into their own hands, leading to serious conflicts between intensive shrimp farmers and IMS or extensive farmers. 
The key similarity in off-farm RMPs in the two cases is that farmer groups collaborated in evaluating input quality, which suggests that this type of collaboration is common to farmers with both open and closed systems. In Kung Krabaen Bay, farmers with Thai GAP-7401 certification, a form of group certification run by the Thai government (see Samerwong et al., 2018), helped each other sample feed quality. In Kien Vang Forest selection of post-larvae was an activity shared among neighbours, relatives, Selva Shrimp certified farmers and Cooperative members. Farmers assessed quality together with others and bought post-larvae collectively, not only to save costs, but also to use the knowledge of other farmers and share risk information.

A notable difference in the nature of collectively practised RMPs in the two areas is that in Kien Vang Forest these were generally initiated by individual farmers, while in Kung Krabaen Bay, off-farm RMPs practised collectively were mostly requirements from membership of formal farmer groups. For example, the Centre initiated collective removal of seaweed from the irrigation canal, a mandatory activity for all irrigation system users.

\subsection{The spaces between: Communication about environmental risks}

In both cases communication about risks between farmers appeared to be an important component of environmental risk management, particularly for managing disease. Farmers in both areas stated that it was important to share information about diseases with other farmers, presumably because a significant amount of environmental risks farmers faced were risks transferred between farms. In both areas roughly $16 \%$ of risks described were those transferred between farms.

In both cases neighbouring farmers communicated about disease and shared solutions, indicating a shared level of trust. Seven farmers in Kung Krabaen Bay mentioned that they communicated with neighbours when encountering disease. In Kien Vang Forest, half of the respondents said they communicated with other farmers about disease. A quarter of farmers described how they shared information regarding disease through daily communication with farmers who shared an input canal, thereby warning other farmers when water was unsuitable to take in. Farmers in both areas consulted each other about solutions.

Though there appeared to be an informal understanding of the value of communicating disease risks with neighbours, there was no formal structure for communication. In both areas, communication generally occurred between individuals connected through familial ties, common species cultivated, or vicinity of farms. However, in Kien Vang Forest there were also examples of farmers warning others in a collective context; through Farmer Association meetings, in Selva Shrimp certification groups, and in Dai Hiep Cooperative. Interestingly, in Kung Krabaen Bay the more formalised farmer groups, like irrigation system user groups and Kung Krabaen Bay Fisheries Cooperative, did not function as groups for risk communication.

In both areas, a number of spatial and scale aspects influenced communication structure and collaboration between farmers. More than half of respondents in Kung Krabaen Bay stated that the irrigation canal acted as a boundary for communication, with farmers only communicating with farms on the same side of the canal. Some farmers shared water inlets, reservoirs or sedimentation ponds with neighbours, which required collaboration.

Though the scale of farms in Kien Vang Forest is not comparable to Kung Krabaen Bay, the spatial structure of communication was in some ways similar. Farms were relatively large and far apart. More than $50 \%$ of respondents claimed they seldom or never communicated with farmers on the other side of their input canal, because they were too far away.

A key difference between the two areas was the interaction between aquaculture actors in the landscape. Though there was clear variation across farms in Kung Krabaen Bay in terms of success rate, species cultured, level of technology and management practices applied, the seawater irrigation system resulted in equal access to good quality water and the removal of cross contamination of farms through water. Contrastingly, in Kien Vang, IMS and extensive farmers shared their landscape with intensive shrimp farms, hatcheries and factories, forming a hybrid landscape and creating, from the perspective of respondents, winners and losers. There was a high sense of hostility towards intensive shrimp farms. Intensive shrimp farmers were repeatedly accused of illegally dumping untreated wastewater. There was little communication between intensive farmers and interviewed farmers, and respondents perceived that intensive shrimp farms physically and socially closed themselves off from other farms.

\section{6 | DISCUSSION}

The open and closed systems compared in this research illustrate how social and spatial configurations of environmental risk management lead us to question some assumptions about open and closed systems, and in turn the formation of areabased management (cf. Bush et al., 2010; Joffre et al., 2015; Vandergeest et al., 2015). More specifically, the close 
association of closed systems with traditional spatial planning through zoning (Figure 3a), assumes the homogenisation of risk in combination with strong (external) planning and control over shared infrastructure; and the association of open systems with landscape approaches (Figure 3b), assumes full integration and communication between land users at a broad and encompassing scale. We question this dichotomy based on three observations.

First, the spatial configuration of environmental risks and RMPs demonstrates a focus on the farm. In both cases the majority of environmental risks identified and therefore acted upon by farmers were those flowing from the environment to the farm. The urgency to address risks off-farm appears to increase the more open systems are, and, as hypothesised, offfarm risk management is applied more in open systems than in closed systems. However, the configuration of off-farm RMPs in open systems does not suggest that farmers with open systems proactively organise the mitigation of risks outside their farm. Instead, off-farm strategies are applied to protect farms from acute environmental risks that have a direct impact on production.

Second, while farmers do recognise off-farm risks, recognition alone does not result in collectively practised risk management strategies at an area level. In the case of Kung Krabaen Bay, farmers were embedded within a wider irrigation system that was controlled by the government, which arguably removed the need for farmers to address key water quality risks. Reflecting research by Bush et al. (2010), the relatively high degree of control these farmers have over flows on and off their farms, coupled with the high degree of government oversight at the landscape level, means they have less need to negotiate with surrounding farmers about water management. In contrast, the open production systems in Kien Vang Forest, with weaker government oversight, did encourage the need to communicate about shared risks and at times these were addressed collaboratively at a very local scale. But in contradiction to our hypothesis and the expectations presented in Bush et al. (2010), this communication did not translate into proactively shared risk management at a broad landscape level.

Third, it appears that unlike the ideal notion of integrated landscape management (e.g., Freeman et al., 2015; Tomich et al., 2011), farmers do not appear able to build relations with surrounding land users. For example, IMS and extensive farmers in Kien Vang Forest did not communicate effectively with intensive shrimp farmers, who they believed to be responsible for water pollution. Instead, intensive shrimp farmers were described as "closed" and communication with them often led to conflict. Hence, IMS and extensive farmers did not appear to create effective fora for negotiation with other land users in the absence of external actors and, in contradiction to our hypothesis, the landscape's diversity did not advance capacity for self-organisation. The fragmented social networks involving different kinds of farmers across the landscape presumably interpret environmental risks differently, resulting in the existence of multiple spaces of risk and hindering the emergence of a landscape-scale approach.

These observations demonstrate the need to rethink the development and application of area-based approaches for both closed and open systems, taking into account the most effective socio-spatial scale of shared risk management; and the

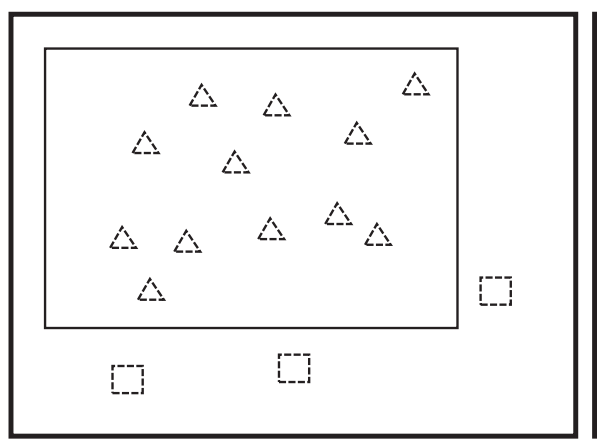

(a) Traditional spatial planning approach

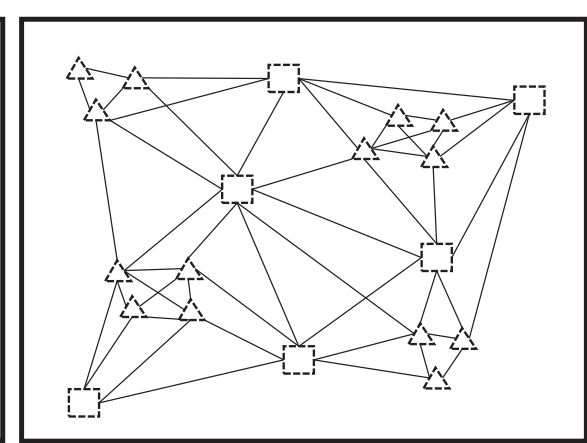

(b) Integrated landscape management approach

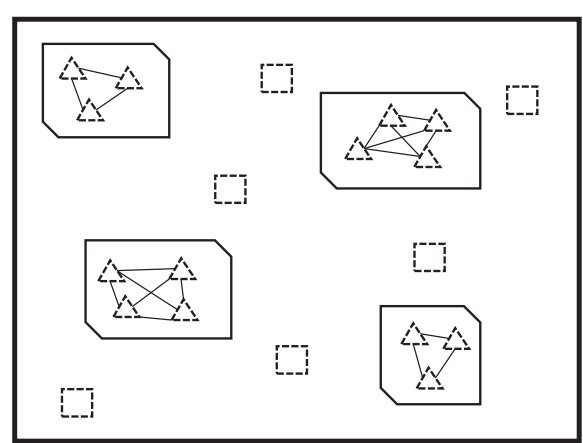

(c) Networked clusters of homogenised environmental risk management

FIGURE 3 Models of area-based management in aquaculture. 
coordinating role of external actors, such as the government, in managing shared infrastructure aimed at mitigating common risks. The consequence is that area-based management is unlikely to emerge, spontaneously or externally managed, at an all-encompassing landscape level, where there is maximum diversity of production systems, risks and competition between farmers. Instead, the results indicate that risk homogenisation, and therefore an effective scale of area-based management, is best realised at scales that reflect both the biophysical dimensions of risk and the shared experience of farmers to collectively mitigate these risks.

These observations open up the possibility of a third way of conceptualising spatial models of area-based aquaculture management for both closed and open systems. Instead of designation of aquaculture zones or all-encompassing integrated landscape models of area-based management (Figures 3a and 3b), the results suggest an alternative model based on a nested set of areas or "compartments" within a landscape defined by the socio-spatial extent of shared risks (Figure 3c). These compartments do not as such meet the wider landscape level goals of area-based management by linking all risks and production activities in an area. Instead they are defined by scalar concordance of the biophysical extent of environmental risks, including shared infrastructures to mitigate these risks, and the social experience of these risks. Based on our findings, it is the social dimension that provides a starting point for the design of these compartments and is therefore key to their effectiveness. Once established, these compartments can be scaled up by establishing, with assistance from external institutions, networks that can proactively manage certain environmental risks shared across the landscapes.

\section{7 | CONCLUSION}

The results confirm the basic premise of area management; aquaculture farms are undoubtedly embedded, physically and socially, into their surroundings. But while sharing environmental risks through collective risk management strategies is a worthy ambition in aquaculture management, it is not necessarily dealt with effectively through area-based approaches at a broad and holistic landscape scale. This leads us to two main conclusions on how research and practice on the development of area-based management should proceed.

First, "areas" are best defined by the socio-spatial extent of farmer networks within which the interpretation of risk is homogenous. This does not mean that the biophysical dimensions of aquaculture landscapes are unimportant. What it stresses is that the actions of and cooperation between farmers to mitigate risks are driven by shared and therefore social interpretations and experiences. Recognising this offers an entirely new and fundamentally social starting point for the definition of area management units in the aquaculture sector, upon which management activities and risk assessments can be built.

Second, nested socio-spatial areas should be seen as building blocks for the management of wider landscapes. This research presents a socio-spatial approach to understanding risk management, which is fundamentally different from existing conceptualisations of area management. This approach appears as some kind of middle ground between, on the one hand, spatial planning approaches based on an understanding of the landscape's ecological functions and, on the other hand, utopian views of integrated approaches advocating the full integration of social and economic activities across landscapes. We argue that an understanding of the social connectivity between farmers is as important as understanding the landscape's physical characteristics, as it is these social relations interacting with environmental risks which shape shared environmental risk management in space. As such, we propose networked clusters of farmers organised around homogenised environmental risks as an alternative starting point for understanding and scaling up area management in aquaculture.

Though we are confident that the manner in which farmers address environmental risks can be explained by the interpretation of shared environmental risks, differences in terms of culture, political history and institutional context may influence how environmental risks are managed. For example, the failure of collectivisation in Vietnam (for details, see Ha \& Bush, 2010; Ha et al., 2013) may very well influence farmer decisions to address environmental risks collectively. Further research into how such contextual factors influence shared environmental risk under conditions of area management would therefore be valuable.

More directly, further research is needed to provide better understanding of the extent to which external actors can stimulate collaboration between farmers to collectively manage environmental risks across landscapes. The public sector's inherent capacity to formalise institutions and delineate areas, the private sector's economic imperatives for risk management, and the moral authority of NGOs appear to result in different approaches. Insight into how each of these actors can organise and facilitate risk management beyond the farm would help further our understanding of the potential of area-based management in aquaculture, and in other food sectors. 


\section{ACKNOWLEDGEMENTS}

We thank all farmers and other respondents who participated in this research. We also wish to extend our appreciation to the Kung Krabaen Bay Royal Development Study Centre and the Kien Vang Forest Management Board for facilitating access to the communities and for logistical support. Finally, we thank two anonymous reviewers for their constructive comments. Research for this article was conducted through the SUPERSEAS project, funded by The Netherlands Organisation for Scientific Research (NWO) and New Directions in Environmental Governance (NDEG) at the York Centre for Asian Research. The preparation of this paper was supported by the CGIAR Research Program on Fish Agrifood Systems (FISH).

\section{ORCID}

Mariska J. M. Bottema iD http://orcid.org/0000-0003-3419-0087

\section{REFERENCES}

Adger, W. N. (2003). Social capital, collective action, and adaptation to climate change. Economic Geography, 79, 387-404. https://doi.org/ 10.1111/j.1944-8287.2003.tb00220.x

Aguilar-Manjarrez, J., Soto, D., \& Brummett, R. (2017). Aquaculture zoning, site selection and area management under the ecosystem approach to aquaculture. A handbook. Rome, Italy: FAO and World Bank Group.

Ahsan, D. A. (2011). Farmers' motivations, risk perceptions and risk management strategies in a developing economy: Bangladesh experience. Journal of Risk Research, 14, 325-349. https://doi.org/10.1080/13669877.2010.541558

Anh, P. T., Bush, S. R., Mol, A. P. J., \& Kroeze, C. (2011). The multi-level environmental governance of Vietnamese aquaculture: global certification, national standards, local cooperatives. Journal of Environmental Policy \& Planning, 13, 373-397. https://doi.org/10.1080/1523908x. 2011.633701

Aquaculture Stewardship Council (2014). ASC shrimp standard - version 1.0. Utrecht, The Netherlands: Aquaculture Stewardship Council.

Arthur, J. R., Bondad-Reantaso, M. G., Campbell, M. L., Hewitt, C. L., Phillips, M. J., \& Subasinghe, R. P. (2009). Understanding and applying risk analysis in aquaculture. A manual for decision-makers. Rome, Italy: FAO.

Bear, C. (2013). Assembling the sea: Materiality, movement and regulatory practices in the cardigan bay scallop fishery. Cultural Geographies, 20, 21-41. https://doi.org/10.1177/1474474012463665

Bergfjord, O. J. (2009). Risk perception and risk management in Norwegian aquaculture. Journal of Risk Research, 12, 91-104. https://doi.org/ $10.1080 / 13669870802488941$

Best Aquaculture Practices (2014). Aquaculture facility certification finfish and crustacean farm standard - Issue 2 Revision 3 November 2016 (p. 43). Portsmouth, VA: Global Aquaculture Alliance.

Blueyou Consulting Ltd (2016). Selva shrimp: A sustainable aquaculture program. Zurich, Switzerland: Blueyou Consulting Ltd.

Boonsong, K. (1997). An integrated planning and management framework for the sustainable development of shrimp farming in Kung Krabaen Bay, Chantaburi province, Thailand. (Doctor of Technical Science PhD Thesis), Asian Institute of Technology, Bangkok, Thailand. (STAR-97-1)

Bostock, J., McAndrew, B., Richards, R., Jauncey, K., Telfer, T., Lorenzen, K., Little, D., Ross, L., Handisyde, N., Gatward, I., \& Corner, R. (2010). Aquaculture: Global status and trends. Philosophical Transactions of the Royal Society of London. Series B, Biological sciences, 365, 28972912. https://doi.org/10.1098/rstb.2010.0170

Bush, S. R., van Zwieten, P. A. M., Visser, L., van Dijk, H., Bosma, R., de Boer, W. F., \& Verdegem, M. (2010). Scenarios for resilient shrimp aquaculture in tropical coastal areas. Ecology and Society, 15, 26. https://doi.org/10.5751/ES-03331-150215

Elliott, J. R., \& Pais, J. (2006). Race, class, and Hurricane Katrina: Social differences in human responses to disaster. Social Science Research, 35, 295-321. https://doi.org/10.1016/j.ssresearch.2006.02.003

Freeman, O. E., Duguma, L. A., \& Minang, P. A. (2015). Operationalizing the integrated landscape approach in practice. Ecology and Society, 20, 24. https://doi.org/10.5751/es-07175-200124

GLOBAL G.A.P. (2012). Interpretation guideline Thailand - Integrated farm assurance control points and compliance criteria version: IFA 4.0 (p. 187). Cologne, Germany: GLOBAL G.A.P. c/o FoodPLUS GmbH.

Ha, T. T. T., \& Bush, S. R. (2010). Transformations of Vietnamese shrimp aquaculture policy: Empirical evidence from the Mekong Delta. Environment and Planning C: Government and Policy, 28, 1101-1119. https://doi.org/10.1068/c09194

Ha, T. T. T., Bush, S. R., \& van Dijk, H. (2013). The cluster panacea? Questioning the role of cooperative shrimp aquaculture in Vietnam. Aquaculture, 388-391, 89-98. https://doi.org/10.1016/j.aquaculture.2013.01.011

Ha, T. T. T., van Dijk, H., \& Bush, S. R. (2012). Mangrove conservation or shrimp farmer's livelihood? The devolution of forest management and benefit sharing in the Mekong Delta. Vietnam. Ocean \& Coastal Management, 69, 185-193. https://doi.org/10.1016/j.ocecoaman.2012.07.034

Ha, T. T. P., van Dijk, H., \& Visser, L. (2014). Impacts of changes in mangrove forest management practices on forest accessibility and livelihood: A case study in mangrove-shrimp farming system in Ca Mau Province, Mekong Delta, Vietnam. Land Use Policy, 36, 89-101. https://doi.org/doi:10.1016/j.landusepol.2013.07.002 
Hardaker, J. B., Huirne, R. B. M., \& Anderson, J. R. (1997). Coping with risk in agriculture. Wallingford, CT: CAB International.

Joffre, O. M., Bosma, R. H., Bregt, A. K., van Zwieten, P. A. M., Bush, S. R., \& Verreth, J. A. J. (2015). What drives the adoption of integrated shrimp mangrove aquaculture in Vietnam? Ocean and Coastal Management, 114, 53-63. https://doi.org/10.1016/j.ocecoaman.2015.06.015

Joffre, O. M., Marijn Poortvliet, P., \& Klerkx, L. (2018). Are shrimp farmers actual gamblers? An analysis of risk perception and risk management behaviors among shrimp farmers in the Mekong Delta Aquaculture, 495, 528-537. https://doi.org/10.1016/j.aquaculture.2018.06.012

Kidd, S., \& Shaw, D. (2013). Reconceptualising territoriality and spatial planning: Insights from the sea. Planning Theory \& Practice, 14, 180197. https://doi.org/10.1080/14649357.2013.784348

Kjærnes, U. (2006). Trust and distrust: Cognitive decisions or social relations? Journal of Risk Research, 9, 911-932. https://doi.org/10.1080/ 13669870601065577

Le Bihan, V., Pardo, S., \& Guillotreau, P. (2013). Risk perception and risk management strategies of oyster farmers. Marine Resource Economics, 28, 285-304. https://doi.org/10.5950/0738-1360-28.3.285

Lebel, L., Lebel, P., \& Lebel, B. (2016). Impacts, perceptions and management of climate-related risks to cage aquaculture in the reservoirs of Northern Thailand. Environmental Management, 58, 931-945. https://doi.org/10.1007/s00267-016-0764-5

Lo, A. Y., \& Chan, F. (2017). Preparing for flooding in England and Wales: The role of risk perception and the social context in driving individual action. Natural Hazards, 88, 367-387. https://doi.org/10.1007/s11069-017-2870-y

Massey, D. (2005). For space. Thousand Oaks, CA: Sage.

Murdoch, J. (1998). The spaces of actor-network theory. Geoforum, 29, 357-374. https://doi.org/10.1016/S0016-7185(98)00011-6

Naturland (2016). Naturland standards for organic aquaculture - Version 05/2016 (p. 37). Gräfelfing, Germany: Naturland - Registered Association for Organic Agriculture.

Piamsomboon, P., Inchaisri, C., \& Wongtavatchai, J. (2015). White spot disease risk factors associated with shrimp farming practices and geographical location in Chanthaburi province, Thailand. Diseases of Aquatic Organisms, 117, 145-153. https://doi.org/10.3354/dao02929

Quoc Vo, T., Kuenzer, C., \& Oppelt, N. (2015). How remote sensing supports mangrove ecosystem service valuation: A case study in Ca Mau province. Vietnam. Ecosystem Services, 14, 67-75. https://doi.org/10.1016/j.ecoser.2015.04.007

Richard Eiser, J., Bostrom, A., Burton, I., Johnston, D. M., McClure, J., Paton, D., ... White, M. P. (2012). Risk interpretation and action: A conceptual framework for responses to natural hazards. International Journal of Disaster Risk Reduction, 1, 5-16. https://doi.org/10.1016/j.ijdrr. 2012.05.002

Samerwong, P., Bush, S. R., \& Oosterveer, P. (2018). Implications of multiple national certification standards for Thai shrimp aquaculture. Aquaculture, 493, 319-327. https://doi.org/10.1016/j.aquaculture.2018.01.019

Satumanatpan, S., Thummikkapong, S., \& Kanongdate, K. (2011). Biodiversity of benthic fauna in the seagrass ecosystem of Kung Krabaen Bay, Chantaburi Province, Thailand. Songklanakarin Journal of Science and Technology, 33, 341-348.

Sayer, J., Sunderland, T., Ghazoul, J., Pfund, J. L., Sheil, D., Meijaard, E., \& Buck, L. E. (2013). Ten principles for a landscape approach to reconciling agriculture, conservation, and other competing land uses. Proc Natl Acad Sci U S A, 110, 8349-8356. https://doi.org/10.1073/pnas. 1210595110

Soto, D., Aguilar-Mangarrez, J., \& Hishamunda, N. (Eds.). (2008). Building an ecosystems approach to aquaculture. FAO/Universitat de les Illes Baleares expert Workshop. 7-11 May, Palma de Mallorca, Spain. Rome, Italy: Food and Aquaculture Organization of the United Nations.

Subasinghe, R., Soto, D., \& Jia, J. (2009). Global aquaculture and its role in sustainable development. Reviews in Aquaculture, 1, 2-9. https:// doi.org/10.1111/j.1753-5131.2008.01002.x

Sustainable Fisheries Partnership (2018). Zonal Approach. Retrieved from https://www.sustainablefish.org/Programs/Aquaculture/Zonal-Approach

The Nature Conservancy (2017). Area-based management. Retrieved from https://www.conservationgateway.org/ConservationPractices/Marine/ Area-basedManagement/Pages/area-based-management.aspx

Tomich, T. P., Brodt, S., Ferris, H., Galt, R., Horwath, W. R., Kebreab, E., Leveau, J. H. J., Liptzin, D., Lubell, M., Merel, P., Michelmore, R., Rosenstock, T., Scow, K., Six, J., Williams, N., \& Yang, L. (2011). Agroecology: A review from a global-change perspective. Annual Review of Environment and Resources, 36, 193-222. https://doi.org/10.1146/annurev-environ-012110-121302

Tookwinas, S., \& Songsangjinda, P. (1999). Water quality and phytoplankton communities in intensive shrimp culture ponds in Kung Krabaen Bay, Eastern Thailand. Journal of the World Aquaculture Society, 30, 36-45. https://doi.org/10.1111/j.1749-7345.1999.tb00315.x

Vandergeest, P., Ponte, S., \& Bush, S. (2015). Assembling sustainable territories: Space, subjects, objects, and expertise in seafood certification. Environment and Planning A, 47, 1907-1925. https://doi.org/10.1177/0308518x15599297

Waite, R. B. M., Brummett, R., Castine, S., Chaiyawannakarn, N., Kaushik, S., Mungkung, R., Nawapakpilai, S., \& Phillips, M. (2014). Improving productivity and environmental performance of aquaculture. Washington, DC: World Resources Institute.

World Bank Group (2016). Agricultural sector risk assessment: Methodological guidance for practitioners. Washington, DC: World Bank Group.

How to cite this article: Bottema MJM, Bush SR, Oosterveer P. Moving beyond the shrimp farm: Spaces of shared environmental risk? Geogr J. 2018;00:1-12. https://doi.org/10.1111/geoj.12280 